\title{
Environmental (Art) Design VS Interior and Spatial Design: A dialogue between Chinese and Italian design disciplines
}

\author{
Yeqiu Yang ${ }^{1 *}$, Luca Guerrini ${ }^{1}$ \\ ${ }^{1}$ Department of Design, Politecnico di Milano, Milan, 20158, Italy
}

\begin{abstract}
The relationship between China and Italy has ever been stronger for academic exchanges to flourish. Vital exchange of teachers and students among design universities has soared to paramount levels. With this, beginning in 2007, both Chinese and Italian higher education institutions have established the 'double master's degree programs in design', with the corresponding degrees being 'environmental (art) design' and 'interior and spatial design' respectively. Meanwhile, there are great strides, followed by demands to strengthen the understanding of the respective cultures, language, and methods of both design institutions. This article aims to assist and facilitate a dialogue of understanding between the two design cultures by analyzing the current status and the evolution of their disciplines in both nations. This research may provide a common basis for the innovation in the field in both countries and contributing useful theoretical notions for the education of design.
\end{abstract}

\section{The 'Honeymoon' period of cultural exchange}

China and Italy, an Eastern and a Western civilization connected by the ancient 'Silk Road', are essential partners of the 'Belt and Road Initiative'[1-2]. In '2014 China-Italy Science, Technology \& Innovation Week' at Politecnico di Milano (PoliMi), Chinese Premier Li Keqiang promoted this strategy- in his speech - the 'Integration of the Wisdom of Chinese and Italian design'[3]. In 2016, the former Prime Minister of Italy, Matteo Renzi, visited Tongji University to celebrate the 10th anniversary of the establishment of the Sino-Italian Campus[4]. In the same year, the Chinese Ministry of Culture and Tourism promulgated the 'Belt and Road Cultural Development Action Plan', which aims to promote the development of cultural exchanges, cultural dissemination, and cultural trade innovation among countries along the route[5]. In February 2017, Tsinghua and PoliMi established the 'Sino-Italian Design Innovation Hub' in Milan. In 2018, Tsinghua University established an overseas institute of art and design in Milan[6]. In 2019, Tongji University also established an overseas campus in Milan and set up the 'Double-Degree PhD Program in Design' with PoliMi[7].

Today, Italy is considered as the closest European nation in terms of cooperation with China in the field of design education. Since 2007, China's Tongji University and Tsinghua University have successively signed a series of 'Double-Degree Programs' with PoliMi in Italy[8]. Under the framework of these programs, China's
'Environment (Art) Design' corresponds to Italy's 'Interior and Spatial Design'.

Confucius said “因材施教” (Teach in accordance with different aptitudes). He believed that according to different students' cognitive level, learning ability, and other measures, the teachers should choose the appropriate learning method that matches the student's peculiarities. Therefore, the prerequisite to enhance the design culture exchanges between the two countries is the understanding of each other's design background, history, and objectives. These are the basis for the development of educational and research activities.

\section{Design discipline positioning and education system}

First of all, the two countries have great differences in the design discipline positioning. According to the discipline catalog of the Ministry of Education (MOE) of Peoples' Republic of China, 'Design' (code 1305) is a subdiscipline of 'Art' (code 13), and 'Environmental Design' (code 130503) is a sub-discipline of 'Design'. Design is a foreign term for China, and it has been phrased by 'Image', 'Decoration', 'Arts and Crafts', 'Practical Art', 'Applied Art', 'Art design', etc.[9]. In the Chinese context, Design and Art are inextricably linked. Based on China's disciplinary frameworks, 'Design' is a branch of 'Art'.

However, in the latest Italian discipline catalog of Ministry of Education, University and Research (in Italian 'Ministero dell' Istruzione, dell' Università e della Ricerca', in short MIUR), 'Design' (code ICAR / 13) belongs to the field of 'Civil Engineering and Architecture'

\footnotetext{
*Corresponding author's e-mail: Yeqiu.Yang@polimi.it
} 
(code Area 08)[10], in fact, it is a branch of 'Architecture'. The School of Design of PoliMi is the earliest and most comprehensive institution in Italy with the Bachelor's Master's - $\mathrm{PhD}$ degree programs in design. Its $\mathrm{PhD}$ program was the original 'Doctoral Program in Industrial Design', established in 1990 as part of Architecture education[11]. The vast majority of design teachers in this institution hold a Master's or a PhD degree in architecture.

Secondly, higher education institutions of the two countries have different system frameworks. Most of the higher education institutions in China are public institutions, and very few are private ones that under the strict control of the MOE[12]. As a result, the graduation degree certificates of higher education institutions must be issued solely by the MOE, and the names of degree programs also must be consistent on the degree certificates. Also, the new taught disciplines in higher education institutions must be approved by the MOE. For example, 'Environmental Design' as a name of the degree program must be adopted in all Chinese public and private higher education institutions.

However, in Italy, both public and private institutions offer a variety of design degree programs. For example, a two-year 'Interior and Spatial Design' Master's degree program established in PoliMi, more focuses on fostering top theoretical talents. As a public institution, PoliMi gravitates towards an academical approach in teaching; in contrast, the Domus academy established a one-year 'interior Design' Master's degree program that is oriented towards design practice and integrated closely with the market. Domus' teachers are mostly frontier industrial designers, and this background allows them to bring reallife industrial applications in teaching.

By comparing the positioning of design disciplines in China and Italy, we can see two different paths of design, one originating from arts and crafts and the other from architecture. Each path represents a different understanding and way of thinking about design culture. At the same time, modern 'design' is still a young subject for every country. Definitions and interpretations change from place to place, but it is gradually becoming a normative research field. In the context of globalization, the authors aspire to promote a 'common ground' upon which all scholars can discuss together on a global level.

Through the comparison of educational systems, we can see that the Italian education system allows more flexibility by providing the students with diverse choices in terms of institution types. However, most of the higher education institutions of design in China are public, and there is no complete autonomy in the construction of the disciplines, both in public and private institutions. The Chinese public and industry have not yet accepted graduates' degrees from private institutions. In contrast, in Italy, private higher education institutions like the Domus Academy, New Academy of Fine Arts, Istituto Marangoni, etc. are popular among students, and their degrees are recognized as equivalent to their public counterpart by Italian society and the market[13]. As we know, design theory and design practice are equally important, and we should give students more study choices. Hence, the coexistence of public and private institutions with different purposes is essential.

Another challenge for the two countries is the language barrier. China and Italy are both countries with a long history and a rich cultural background; neither of them uses English as a native or an official language. This puts both parties at a considerable disadvantage, as in the context of globalization, international rankings, exchange of information, international students, and research collaboration, the language barrier has become a challenge that most universities must face[14]. In 2012, PoliMi took a very radical approach, by proposing to the MIUR to teach 'All courses in English'. After six years of deliberations, the application was rejected[15]. The State Council has concluded that the 'Italian Language' is of paramount importance in the preservation of the country's cultural heritage, equality, freedom of teaching, and university autonomy. To this day, any public Italian higher educational institution that provides courses taught in English must have the equivalent courses taught in Italian.

\section{Environmental (Art) Design}

In the western context, 'Environmental Art' refers to a specific branch of contemporary art, while 'Environmental Design' is often associated with environmental protection, recycle, and ecology. In the Chinese context, however, the Environmental (Art) Design has a completely different meaning from its western counterpart. At present, there are two different names referred to this discipline in the Chinese academic circles: 'Environmental Art Design' and 'Environmental Design'[16].

Initially named 'Interior Design', the Environmental (Art) Design has a history of about 60 years. Today, more than 1,000 comprehensive universities and fine art colleges teach this discipline, which is specified into three levels: Bachelor's, Master's, and $\mathrm{PhD}$ degree programs. In the discipline catalog of the MOE, the Environmental (Art) Design has changed names three times, from 'Architectural Decoration Art' (1963), to 'Environmental Art Design' (1987), and finally to 'Environmental Design' (2012). In the official 'Introduction to Degree Discipline and Talent Cultivation First-Class Discipline' in 2013, it was described as follows:

This discipline studies the environmental interaction of nature, man and society, with the main purpose of finding new solutions to optimize the relationship between the three, and consequently improve human life and living environment. The environmental design takes the building as the main body, puts it in a relationship with its environment, and through artistic methods, and engineering techniques improve its internal and external spaces to creates urban and rural landscapes, garden landscapes, interior space and micro-environments. Environmental design requires the investigation and evaluation of its objectives that range from critical technical aspects of the ecological impact of materials and their setting, all the way to its interaction to its design objective, that encompass lots of factors. It emphasizes the 
design concepts of systems and integration, the working method of control and coordination, reasonably formulates the design goal and realizes valuable concepts[17].

This discipline was first founded at the Central Academy of Arts and Crafts (now Academy of Arts \& Design, Tsinghua University), which is the first institution of art and design in China. Today Tsinghua University is considered as the leader in the Chinese design education circles. However, it is also the place where the ambiguity about the name of the discipline is born: the department was named 'Environmental Art Design', but the name of the professional discipline is 'Environmental Design'. The two directors of this department, Zhang Yiman and Zhen Shuyang have argued for decades over the names of
'Environmental Art Design' and 'Environmental Design' [18-19], which has directly led to the two terms often confused in different educational institutions and literature. This confusion of 'two-name for one discipline' results in unprogressive development, leading to no agreement on the definition, boundaries, and teaching goal of this discipline. Moreover, most of the fine art colleges or academies with long history prefer 'Environmental Art Design'. Meanwhile, newly established collages use more often the title 'Environmental Design' [20].

At present, this program from the Tsinghua University is divided into two directions: 'Interior Design' and 'Landscape Design' (table 1), which encloses both the interior and exterior spatial design [21].

Table 1. Course titles of Environmental Design.

\begin{tabular}{|l|l|}
\hline Direction & Courses \\
\hline $\begin{array}{l}\text { Interior } \\
\text { Design }\end{array}$ & $\begin{array}{l}\text { Spatial Design Concepts, Design Expression, Ergonomics, Material Construction and } \\
\text { Technology, Architectural Design Foundation, Furnishings Art Design, Furniture Design, } \\
\text { Environmental Lighting Design, Environmental Colour Design, Environmental Greening } \\
\text { Design, Introduction of Environmental Art Design, Architecture and Garden History in } \\
\text { Chinese and Foreign. }\end{array}$ \\
\hline $\begin{array}{l}\text { Landscape } \\
\text { Design }\end{array}$ & $\begin{array}{l}\text { Spatial Design Concepts, Design Expressions, Landscape Surveys, Architectural Morphology, } \\
\text { Horticultural Foundations, Public Facility Design, Public Art Design, Garden Design, Urban } \\
\text { Design, Urban Planning Principles, Architecture and Garden History in Chinese and Foreign, } \\
\text { Environmental Behavior Psychology Courses. }\end{array}$ \\
\hline
\end{tabular}

\section{$4 \quad$ Interior and Spatial design}

The School of Design of PoliMi is the most prominent design institution in Italy[22]. It offers the degree program in the field of 'design of space' at the three academic levels, Bachelor's, Master's, and Phd (table 2).

The bachelor's degree program of 'Interior Design' remains unchanged and the teaching language is Italian. The master's degree program is called 'Interior and Spatial Design', evolved originally from 'Interior Design' (adjusted in 2017), the courses are offered in both English and Italian. This master's degree program joined the 'Double Degree' program with Chinese universities, and degrees today are obtained in any of the shared universities and are mutually recognized. The $\mathrm{PhD}$ program is oriented to 'Design for environmental, landscape, and mobility' research direction, and it is done in the English language.

In the 'Interior Design' manual of the bachelor's degree program, the description is shown as follows:

The educational goals of the Laurea (bachelor's degree) in Interior Design are to supply students with the skills needed to carry out the multiplicity of technical-design tasks supporting interior design in their many configurations and accordance with the various phases ranging from creation to meta-design and planning right through to implementation work monitoring. Students learn the methods and techniques required to draw up projects that integrate type, formal, functional and technological aspects from the starting point of context analysis with a special focus on the use of languages representing contemporary scenarios[23].

In the 'Interior and Spatial design' manual of the Master's degree program, the description is shown as follows:

The aim is to train designers capable of intervening creatively with projects in the contexts set out above, in functional, aesthetic-formal, technical and technological definitions of space, of the relationships between users and space, the relationships between space and context; working to enhance the interior spaces of the existing architectural heritage by modifying environmental quality and image often with reversible action and always in any case in an innovative interpretation of the nature of space and client demands[23]. 
Table 2. Course of 'Interior Design' and 'Interior and Spatial Design'.

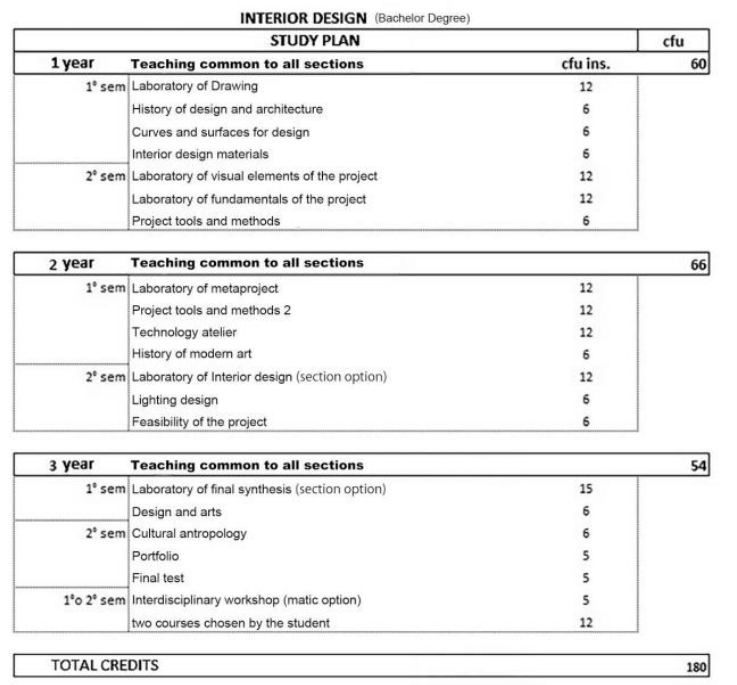

\section{From 'Interior' to 'Environmental' and 'Spatial'}

Environmental (Art) Design and Interior and Spatial Design are the two corresponding degree programs both in China and Italy, respectively, and they are both developed from the original 'Interior design' degree program. Interestingly, their evolution share some common reasons.

\subsection{From 'Interior' to 'Environmental'}

The change of discipline name happened at the Central Academy of Arts and Crafts (now Academy of Arts \& Design, Tsinghua University). There is a group of renown scholars, led by Xi Xiaopeng, Pan Changhou, Zhang Yiman proposed the concept of 'Environment' from the basis of Interior Design, summarizing their ideas in the following levels [24]:

- On the physical spatial level. 'Interior' or 'Architectural' were no longer terms that could accurately indicate the object of the design. 'Environment' was better suited to cover the 'interior' and 'exterior' spaces.

- On the cognitive level. Scholars started to realize that this discipline should not only beautify local details but also systematically propose new design solutions for human living spaces with integrity.

- On the philosophical level. Scholars put forward the idea of 'environmental philosophy', which emphasizes people, society, and the environment coexisting in harmony.

- On the social-ecological level. From the 1970s of the 20th century, the new concept of 'environmental awareness' and 'environmental protection' have started rising, and this new ecological sensibility also echoed with the discipline.

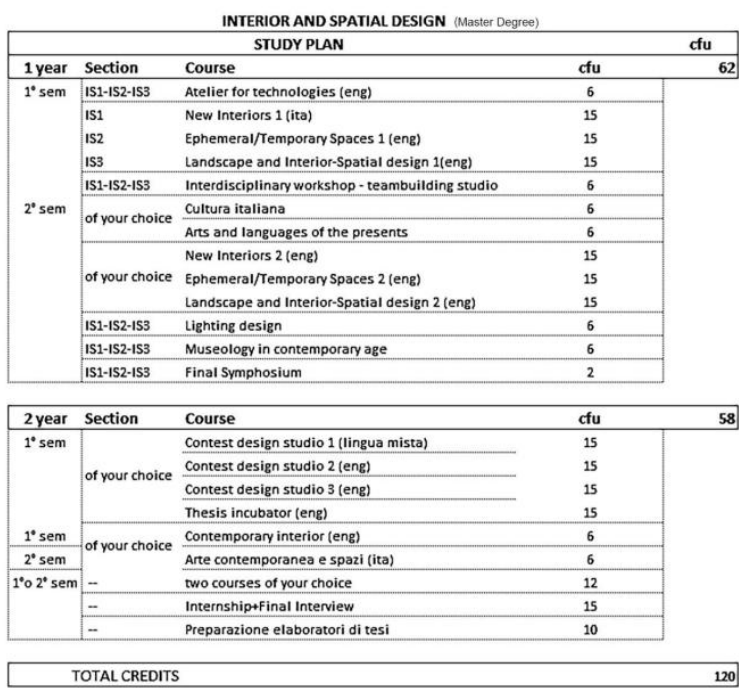

\subsection{From 'Interior' to 'Spatial'}

The PoliMi has established Bachelor's and Master's Degree programs in Interior Design since 2002. In 2017 , they changed the name of the Master's Degree program to 'Interior and Spatial Design'. Andrea Branzi, Fulvio Irace, Giovanna Piccinno and other scholars proposed the concept of 'spatial' based on interior design for the following reasons[25-27]:

- 'Interior Design' in English is not equivalent to 'Design Degli Interni' in Italian, and 'Design Degli Interni' in Italian context cannot be as accurate as that in English.

- Interior Design is generally considered to be second only to architecture, but it is actually a complex discipline that organically links design and architecture itself. The discipline should also include those outdoor spaces, which can be viewed as open-air indoor spaces, such as squares.

- The discipline has an elusive multi-disciplinary nature. It is often redefined with the influence of modern life and highlights the new pattern of social change.

\section{Discussion: rethinking in the context of emerging design}

Nonetheless, 'Environmental' and 'Spatial', both have very 'broad' concepts, and their core and boundaries are still tough to define. They are inextricably connected to other disciplines, like urban design, architecture, interior design, and landscape design, but they don't belong to any of them; they resemble more of a synthesis of the disciplines mentioned above. This ambiguity of two discipline boundaries makes it impossible for higher education institutions to train qualified field experts in a short amount of time. In order to improve this education situation, it is necessary to establish new perspectives and to undergo a radical transformation in the way of thinking. 
The PoliMi DESIS Lab has done a lot of research on the integration of spatial design and service design, and proposed the use of the Product Service System approach to integrate those 'tangible' and 'intangible' disciplines[28]. This transdisciplinary approach seems to be very promising, although its validity has yet to be proven.

As Don Norman and others said[29], 'the major problems facing humanity today involve complex systems of stakeholders and issues, and the modern design has grown from a focus on products and services to a robust set of methods that are applicable to a wide range of societal issues'. The focus of emerging design has shifted away from 'objects' (products, services, and systems) and toward 'ways of thinking'[30]. Therefore, under the context of this huge revolution, will Environmental (Art) Design and Interior and Spatial Design have new life and development?

\section{Acknowledgments}

Initial ideas in this paper were presented in an address at the 10th $\mathrm{PhD}$ colloquium on design research at Hunan University in 2019. This paper is supported by the China Scholarship Council (CSC, File No. 201807820027), which sponsored the first author's PhD study at the Politecnico di Milano.

\section{References}

1. Liu, X. (2010). The Silk Road in world history. Oxford University Press.

2. Xinhua News Agency. (2019). China, Italy sign BRI MoU to advance connectivity. http://www.xinhuanet.com/english/europe/201903/23/c_137918304.htm.

3. Chinese Government Website. (2014). Milan hotly discusses Li Keqiang's speech: China is by our side. http://www.gov.cn/zhengce/201410/17/content_2766706.htm.

4. Sohu Website. (2016). Ten Years of Cooperation between Tongji University and Italy. https://www.sohu.com/a/113555866 407277.

5. Chinese Government Website. The Ministry of Culture's "Belt and Road" Cultural Development Action Plan (2016-2020). http://www.scio.gov.cn/xwfbh/xwbfbh/wqfbh/35 861/36653/xgzc36659/Document/1551344/15513 44.htm.

6. Tsinghua University. (2018). Sino-Italian Design Innovation Hub and Tsinghua University Milan School of Art and Design officially launched in Milan, Italy. https://news.tsinghua.edu.cn/info/1086/41052.htm.

7. PoliMi Phd Design. http://phd.design.polimi.it/admission.

8. Baidu Baike. (2015). Tongji University SinoItalian College. Retrieved April 30, 2020 https://baike.baidu.com $/$ item $/ \% \mathrm{E} 5 \% 90 \% 8 \mathrm{C} \% \mathrm{E} 6 \% \mathrm{~B}$ 5\%8E\%E5\%A4\%A7\%E5\%AD\%A6\%E4\%B8\%AD
\%Е6\%84\%8F\%Е5\%AD\%A6\%Е9\%99\%A2/48009 48.

9. Zhen, J. (2009). From "Arts and Crafts" to "Art Design". Zhuangshi,12:21-24.

10. Ministry of Education, University and Research.(2015). Decreto Ministeriale 30 ottobre 2015 n. 855.

11. Guerrini, L., \& Volontè, P. (Eds.). (2018). Dialogues on Design: Notes on Doctoral Research in Design 2018. FrancoAngeli.

12. Chinese Ministry of Education. (2015). Higher Education Law of the People's Republic of China. http://old.moe.gov.cn//publicfiles/business/htmlfiles /moe/moe_619/200407/1311.html.

13. Domus Academy Milano. (2020). Accreditation. https://www.domusacademy.com/about/knowdomus-academy/accreditation.

14. Liu,T. (2015). Research on the Applied Transformation and Innovation and Entrepreneurship Training System of Newly-built Undergraduate Universities. Xi'an Jiaotong University Press.

15. Perrone, A. (2018). Caso Politecnico di Milano: studiare in inglese? Sì, ma non togliete l'italiano. https://www.lavocedinewyork.com/arts/linguaitaliana/2018/02/01/caso-politecnico-di-milanostudiare-in-inglese-si-ma-non-togliete-litaliano.

16. Hu, F., \& Zhong, H. (2020). Environmental Design Methods and Their Multidimensional Analysis. Packaging Engineering, 41:20-33.

17. The Sixth Discipline Review Group of the Academic Degrees Committee of the State Council. (2013). Introduction to first-level disciplines for degree award and talent development. Beijing: Higher Education Press.

18. Zhang, Y.(2019). One person, a history of environmental art design. Design,12:92-95.

19. Zhen, S. (2019). 60 Years of Research on Environmental Design in China.Zhuangshi,10,12-19.

20. Cai, J.(1999). Thinking about art and design. Art Observation, 12:11.

21. Academy of Arts \& Design, Tsinghua University. (2020). Department of Environmental Art Design. http://www.ad.tsinghua.edu.cn/publish/ad/2854/inde x.html.

22. School of Design of Polimi. (2020). http://www.design.polimi.it/en/theschool/presentation.

23. Politecnico di Milano. (2020). Educational rules A.Y. 2019/2020.

http://www.design.polimi.it/en/studyingdesign/educational-rules-ay-20192020.

24. Ren, Y. (2018). The Origins of Environment Ideas: The Birth of an Integrated and Systematic Design View. Zhuangshi,1:84-86.

25. Branzi, A. (2006). Weak and Diffuse Modernity: The World of Projects at the beginning of the 21st Century. Skira.

26. Irace, F. (2015). Storie d ,interni. L ,architettura dello spazio domestico moderno, Carocci, Roma. 
27. Lega, E., \& Piccinno, G. (Eds.). (2012). Spatial design for in-between urban spaces. Maggioli.

28. Fassi, D., Galluzzo, L., \& De Rosa, A. (2018). Service+Spatial design: Introducing the fundamentals of a transdisciplinary approach. In ServDes2018. Service Design Proof of Concept, Proceedings of the ServDes. 2018 Conference, 18-20 June, Milano, Italy. Linköping University Electronic Press.

29. Norman, D. A., \& Stappers, P. J. (2015). DesignX: the design of complex sociotechnical systems. SheJi: J. Des. Econ. Innov. 1(2), 83-94.

30. Manzini, E. (2016). Design culture and dialogic design. Design Issues, 32(1), 52-59. 